\title{
On Information Technology and Foreign Language Teaching in Big Data Era
}

\author{
Jihua Fan \\ North China Institute of Science and Technology, China \\ *ruthy12@163.com
}

Keywords: IT; FL teaching; big data

\begin{abstract}
The paper aims to make an exploratory discussion on the application of information technology to foreign language teaching. Combining the properties of language learning and learners' needs, we analyze the potential uses of information technology in language teaching and come to the conclusion that information technology in Big Data era, as the trend of human development, has triggered the emergence of new teaching models such as MOOCs and micro-class, and has provided loads of online teaching resources and individual study tools, thereby transforming the way teachers teach, students learn, and teachers and students interact.
\end{abstract}

\section{Introduction}

Nowadays, information technology (IT) has made data type and amount grow at high speed. At the same time, data sets are increasingly being gathered by cheap and numerous information-sensing devices supported by information technology such as mobile devices, aerial (remote sensing), software $\operatorname{logs}$, cameras, microphones, radio-frequency identification readers, and wireless sensor networks. All this is making human society come into the Big Data era in which people are getting used to web-based activities such as shopping online, reading, writing, reviewing and communicating online. Web-based activities have become the part of our life, naturally changing the way of our learning for the acquisition of information and knowledge is no longer restricted by time and space.

Since its birth, the application of information technology has been recognized in the field of language teaching. On one hand, it is accepted that technological innovations can increase learner interest and motivation; provide students with increased access to target language (TL) input, interaction opportunities, and feedback; and provide instructors with an efficient means for organizing course content and interacting with multiple students. On the other hand, the use of new technology is criticized for it can result in inappropriate input, shallow interaction, and inaccurate feedback; student frustration with software and hardware; distraction from the learning task; and a general over-emphasis on delivery modality over learning objectives. So, in the big data era, it is worthwhile to probe into how to make effective use of information technology in foreign language (FT) teaching and avoid the deficiencies it may bring.

From the perspective of language use and learning, the paper firstly analyzes the potential uses of information technology in language teaching. Then, combining the learners' learning needs, we try to reason out the appropriateness of technology application to FT teaching and learning.

\section{Information Technologies and Language Teaching}

With the growing popularity of modern network and information technology, Big Data have been produced exponentially. It is reasonable to acknowledge that how to utilize the technology and Big Data to increase learner interest and motivation, provide students with increased access to TL input and interaction opportunities would be an important trend of FL teaching reform. However, through the review of over 350 studies, Golonka et al. revealed that, in spite of an abundance of publications available on the topic of technology use in FL learning and teaching, evidence of efficacy is limited [1]. This indicates that, on one hand, the potential of technology use in FL learning and teaching has been widely recognized, on the other hand, its efficacy still needs to be improved. To make full use of 
information technology in FL learning and teaching, we must find its theoretical foundations rooted in FL learning and teaching.

\subsection{Language and FL Learning}

If we say language learning is to learn a language and use it for communication, the first thing we should know is what a language is. The most commonly accepted definition of language is that language is a system of arbitrary vocal symbols used for human communication [2]. From the commonly accepted definition of language, we can easily induce that to learn a language is to learn a system of arbitrary vocal symbols used for human communication. Language learning mainly focuses on foreign language learning and second language learning, their basic distinction is the geographical context in which a language is spoken. Second language refers a non-native language, which is learned or used in second language environment, within a country or speech community where it has official status or recognized function, and is used for education, government, or business within the country. Foreign language is a non-native language, learned or used in a first language environment in one's own country or speech community with little exposure to native use of language or few opportunities to use the language. In this paper, we mainly focus on foreign language learning, especially the learning of English as a foreign language (EFL) in China.

Krashen [3] held that in ideal conditions, successful acquisition of a language is normally the result of a sustained period of time, possibly years, in a naturalistic setting, being surrounded by a language, in its oral and written forms, with comprehensible input directed to the 'novice linguist' by native speakers who actively encourage and patiently support his or her attempts to communicate and who provide referential clues which support the language. In contrast to the ideal described above, foreign language learning lacks a sustained period of learning time and a naturalistic language setting.

\subsection{The Technologies Used in Language Teaching}

Based on the biological, cognitive and sociological properties of human language use and learning, it is supposed that technology use can effectively promote foreign language teaching, for technologies, whether they are low-tech or high-tech, can offer more interactivity than texts only, give students the chance to use a variety of different skills, and enrich the curriculum with interesting content. By using qualitative, self-reported and observational data, a large number of studies have confirmed that learners enjoy using technology in FL learning, that they prefer using technology over more traditional methods and materials, and that technology-based instructions are more effective than traditional ones (e.g. [4], [5]).

In fact, just in the consideration of the biological and sociological properties of human languages, language teaching has applied many communication technologies since their inventions. Televisions, videotapes and audiotapes have been available for use in teaching for at least a few decades. With minor modifications to previous similar technologies, the technologies such as DVD and CD players; digital slide presentation hardware or software have been widely used in language teaching in the past two decades.

Golonka et al. [1] made a review to summarize evidence for the effectiveness of technology use in FL learning and teaching. They categorized the technologies into schoolhouse- or classroom-based technologies (e.g. course management system, interactive white board, ePortfolio), individual study tools (e.g. corpus, electronic dictionary, intelligent tutoring system, grammar checker, automatic speech recognition and pronunciation program), network-based social computing (e.g. chat, blog, internet forum or message board, Wiki) and mobile and portable devices (e.g. PC, iPod, cell phone or smartphone). We find that the technologies reviewed by Golonka et al. [1] are closely related to information technology for they focus on collecting, storing, retrieving, and analyzing information.

Since technology use can make learners be more engaged in the process of learning, the application of technologies to FL teaching is widely advocated. To optimize FL learning by using information technology, it is worthwhile to study its potential in language teaching. 


\section{The Potential of Information Technology in FL Teaching}

Nowadays, the computer is having a major impact on the ways we interact with information and with each other. This makes the IT use in learning and teaching more salient. It is the IT that makes true new learning and teaching models such as network autonomous learning, blended learning, flip teaching, Moocs, SPOC and etc. As for foreign language teaching, the main potential of IT lies in the accessibility of authentic language resources as well as the new online learning and teaching models it provides.

\subsection{Providing Authentic Language Input}

According to Krashen [3], foreign language learning lacks a naturalistic language setting with comprehensible input provided by native speakers who actively encourage and patiently support his or her attempts to communicate and who provide referential clues which support the language. This deficiency can be more or less made up by IT for it can provide an authentic language context in which the target language is used in a naturalistic setting.

In terms of informational resources and tools for language teaching, IT offers the accessibility of language input in a large amount and variety to the contexts of language learning and teaching. According to Pennington [6], IT has the potential for enhancing language learning by the unique properties and variety of the input that are made available by electronic resources such as CD-ROM, networks, and specific hardware and software. IT resources expand the pool of input to language learners and enlarge the language learning context. Table 1 summarizes the features of the expanded language input offered by IT. Such language input guarantees that learners can easily access the authentic language materials and are familiar with the naturalistic settings in which the target language is used.

Table 1. Expanded Language Input Offered by IT.

Quantity of input

Access to input

Diversity of input

Sources of input

Quality of input

Novelty of input

Interaction with input
Enlarged pool of potential input

Enlarged language learning context

Increased variety of input

New sources of information and partners for interaction

Focused, individualized, salient, authentic

New types of input

Qualitatively new ways of accessing information

\subsection{Providing Means for Sharing Authentic Language Input in Class}

Information technology with multimedia capabilities can increase, enhance, and facilitate the provision of rich, comprehensible language input to the learners in the classroom setting (both audio and video). According to Golonka et al. [1] the mainly-used schoolhouse- or classroom-based technologies are course management system (CMS) and interactive white board, which can be described in Table 2:

Table 2 Schoolhouse- or classroom-based technologies

Course Server-based application used to present materials and services required for management system blended or distance learning. Teachers and students access a CMS over a (CMS) network through a web browser, using a menu-driven interface

Interactive white An interactive display that comprises three pieces of equipment: a computer, a board projector, and a display panel.

Course management system (CMS) enables learners to share teaching materials, allowing accessibility to language content and authentic language input at anytime and anywhere. Interactive 
white board incorporates authentic content available on the internet into classroom lessons. These technologies can increase the possibility of that input being processed and integrated into language teaching, and increase the pedagogical quality of input by enhancing access efficiency.

\subsection{Providing More Communicative Models}

The information technology not only makes the diversity and variety of language input available but also offers new sources of information and partners for interaction such as by email, Internet browsing and chat activities, etc. Language learning involves interaction with input and with people. The information technology just provides us network-based communicative models, which can be illustrated in Table 3:

Table 3. Network-based communicative models

$\begin{array}{ll}\text { Chat } & \begin{array}{l}\text { A form of synchronous computer-mediated communication; either text } \\ \text { based or include audio. }\end{array} \\ \text { Social networking } & \begin{array}{l}\text { Social networking enables peer-to-peer communication and } \\ \text { collaboration. }\end{array} \\ \text { Internet forum or message } & \begin{array}{l}\text { An asynchronous system in which messages are sent to multiple } \\ \text { recipients. }\end{array} \\ \text { board } & \begin{array}{l}\text { A web application that displays entries authored by } \\ \text { the blog owner and is visible to other web users }\end{array} \\ \text { Wiki } & \text { A website that allows multiple users to post or edit information }\end{array}$

These communicative models enable communication and collaboration among students or between students and native speakers without constraints of distance or location, allow for synchronous or asynchronous communications and encourage collaborative learning. All this increases learning opportunities and learnability.

\subsection{Providing Individual Study Tools and Devices}

To facilitate language learning, the individual study tools and devices are invented with the help of information technology. The popular individual study tools in FL learning are electronic dictionary, grammar checker, automatic speech recognition (ASR) and pronunciation program, which are described in Table 4.

Table 4 Individual study tools

\begin{tabular}{ll}
\hline Electronic dictionary & A dictionary in electronic form - either handheld or \\
& online \\
Grammar checker & A program designed to evaluate a written text's \\
& well-formedness in terms of grammaticality
\end{tabular}

Automatic speech recognition (ASR) \& A technology that allows a computer to identify the pronunciation program words a person speaks into a microphone.

Electronic dictionaries are more popular among present-day college students than traditional paper dictionaries in FL learning. Grammar checkers can be used in students' writing assignments; however, in order to use this technology effectively, language learners need training. ASR is used to improve learners' FL pronunciation. There are the studies demonstrating that ASR can facilitate the improvement of pronunciation and can provide feedback effectively (e.g. [7], [8]).

The individual study tools can be installed into mobile or portable networkable devices for anytime, anywhere learning. Such devices as personal computer (PC), iPod, cell phone or smartphone can run software for language learning, provide mobile internet access, and facilitate the communication during remote learning activities. 


\section{The Application of Information Technology to FL Teaching}

The development of information technology makes a multitude of computerized resources and tools available to the possible needs of language learners. However, just as Timothy Reagan (see [9]) argued that although new technology can assist language learning, it can not be regarded as a cure-all because in some cases its abuse or misuse can make the learners frustrated in the learning process. To avoid such abuse or misuse, the application of information technology to language teaching should be based on the need of learners and the instruction of teachers.

\subsection{Need-based Use of Information Technology}

FL learning needs authentic input. So, Li \& Chen [9] thought that in such language environment which is not ideal for learning a foreign language, learners should make full use of information technology and use it to dig amount of foreign language resources so as to make up for the deficiency of language learning environment. As for the English majors in China who put more emphasis on language communicative skills and urgent needs for improving their academic writing and reading abilities[10], they can choose network-based communicative models in their learning such as online chat, social networking, internet forum or message board, blog, wiki and cloud-based writing software. In another case, Terrence G. Wile (2015, see [9]) online investigated over 1,600 English learners in China and found although these learners had strong learning motivation, they explicitly expressed that they lacked the learning opportunities, and most of them thought English speaking and listening were their weak points. For such learners, automatic speech recognition (ASR) and pronunciation program may be the best choice to improve their English speaking and listening ability.

In short, it is worthwhile to probe into the effective means to connect the language theoretical constructs with the application of modern educational techniques with considering learners' need in foreign language teaching practice.

\subsection{Instruction-based Use of Information Technology}

Tochon (2015, see [9]) held that the application of new technology to language teaching has side effect such as the health risk and mental stress on the learners, therefore, he warned that learners should not be imprisoned by technology. To avoid the side effect of technology, teachers should give more instruction.

Liu \& Li [9] investigated the learning needs of English majors and found that network has become a new channel used by students for learning English; however, network as a learning model is mostly used by students to collect materials for finishing their homework assignments, watch English films and listen to English music. Generally, the application of network in language learning lack scientific guidance. In grammar learning, Kilıçkaya [11] proves that participants instructed by using both computer-based and teacher-driven grammar instruction supported by computer-based materials score higher than those who receive traditional instruction. Moreover, teacher-driven instruction with computer-based materials in learning adverbial clauses can lead to higher achievement through taking practice beyond the classroom. Zheng, Niiya and.Warschauer [12] proved that although wikis are a promising platform for collaborative learning; wiki-supported collaborative learning cannot function without an effective learning design, and therefore, well-designed instruction is vital to the success of any technology-facilitated learning activities in higher education.

\section{Conclusions}

Information technology has the built-in features for supporting FL teaching. However, the use of technology alone does not guarantee successful learning activities. Pedagogical design of the integration of technology into instruction is important in network-based learning activities. Well-designed instruction is vital to the success of any technology-facilitated learning activities in 
higher education. By applying fundamental principles of language learning, future research should address the affordances that information technology can make for FL teaching and investigate the specific characteristics of technologies that may have differential effects on language skills (such as speaking, listening, reading and writing).

\section{References}

[1] E. M. Golonka et. al, "Technologies for foreign language learning: a review of technology types and their effectiveness", Computer Assisted Language Learning, vol. 27, Jan. 2014, pp. 70-105.

[2] R. Waudhaugh, Introduction to Linguistics, NY: MaGraw-Hill Inc, 1977

[3] S. Krashen, The Input Hypothesis: Issues and Implication, London: Longman Publishing House, 1985

[4] H.T. Hung, "Flipping the classroom for English language learners to foster active learning", Computer Assisted Language Learning, vol.28, pp. 81-96, Jan. 2015, doi:10.1080/09588221.2014.967701

[5] H. C. Huang, "From web-based readers to voice bloggers: EFL learners' perspectives", Computer Assisted Language Learning, vol.28, pp. 145-170, Jan. 2015,

[6] M.C. Pennington, "Cycles of Innovation in the Adoption of Information Technology: A View for Language Teaching”, Computer Assisted Language Learning, vol.17, pp.7-33, Jan. 2004.

[7] D.M. Hardison,. "Generalization of computer-assisted prosody training: Quantitative and qualitative findings". Language Learning \& Technology, vol.8, pp. 34-52, Apr. 2004.

[8] M.W. Tanner \& M.M. Landon (2009). "The effects of computer-assisted pronunciation readings on ESL learners' use of pausing, stress, intonation, and overall comprehensibility". Language Learning \& Technology, vol.13, pp. 51-65, 2009.

[9] L. Chen, M.H. CHEN, "On foreign language education policies in China in the new technology-enhanced environment-Reflections on the 5th international conference on language education policies", Computer-Assisted Foreign Language Education in China vol.162, pp.78-80, May. 2015

[10] Y.Liu, Z.W. Li, "A survey and analysis on the learning needs of English majors who were born in the 1990s", Foreign Languages Research, vol.145, pp. 47-51, May. 2014

[11] F. Kilıçkaya, "Computer-based grammar instruction in an EFL context: improving the effectiveness of teaching adverbial clauses", Computer Assisted Language Learning, vol.28, pp. 325-340, 2015, doi: 10.1080/09588221.2013.818563.

[12] B.B Zheng, M. Niiya and M.Warschauer, "Wikis and collaborative learning in higher education", Technology, Pedagogy and Education, vol.24, pp. 357-374, 2015. 